\title{
A RETÓRICA DO EXAGERO: ESTUDO DA CANTIGA NO 110 DO CANCIONEIRO MARIANO DE D. AFONSO X, O SÁBIO
}

Carla Cristina de Araújo*

$\mathrm{Uni} / \mathrm{BH}$

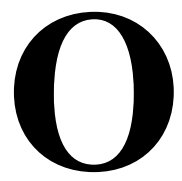

trabalho que pretendo apresentar consta da análise de uma Cantiga de Santa Maria, precisamente a de $n^{0} 110$. A minha leitura incidirá na interpretação das numerosas hipérboles da Cantiga.

Primeiramente, faz-se necessário situar a Cantiga objeto deste estudo dentro da literatura medieval. As Cantigas de Santa Maria são, como se sabe, uma coleção de 429 cantigas religiosas, dedicadas à Virgem Maria, da autoria de D. Afonso X, o Sábio, e um grupo de colaboradores. Além da parte literária, esse Cancioneiro apresenta as composições musicais de cada cantiga, e, ainda, uma iluminura de cada uma delas. Cada iluminura é feita em seqüência de quadrinhos, geralmente seis. As Cantigas de Santa Maria datam da segunda metade do século XIII, e foram compostas em galegoportuguês. Conservaram-se em três códices, compilações manuscritas das Cantigas, que são os seguintes: o Códice Florentino, o Códice Toledano, e dois Códices Escurialenses. Um desses dois últimos, por contar com o maior número de cantigas, partituras e ilustrações, enfim, por ser o mais completo deles, é também chamado Códice Rico. Da transcrição das Cantigas desse Códice é que temos $A s$ Cantigas de Santa María, compiladas e publicadas com um estudo

* Professora do Departamento de Ciências Humanas, Letras e Artes do UNI-BH, mestranda em Literaturas de Língua Portuguesa na PUC Minas. Membro da ABRABLIP. 
introdutório, pelo erudito alemão Walter Mettmann, primeiramente, através da Editora da Universidade de Coimbra e, mais tarde, pela Editora Castália, de Madrid. Seu trabalho, que teve início na década de 50, teve sua primeira publicação portuguesa em três volumes, aos quais ele acrescentou um último, o Glossário, que é o resultado de um trabalho muito cuidadoso de apuração do vocabulário. Nesse último volume, indispensável ao pesquisador ou ao leitor das Cantigas, ele dá o significado das palavras, transcrevendo versos que mostram como essas palavras foram empregadas. A edição de 1986 desse trabalho, publicada pela Clásicos Castalia, de Madrid, é a que serve de referência para este estudo. A essa edição falta o glossário, que seria o quarto volume.

Os poemas são de duas espécies: Cantigas de Milagre e Cantigas de Louvor. Apresentarei um pequeno estudo sobre a Cantiga $\mathrm{n}^{\mathrm{o}} 110$ que, como todas as cantigas numeradas com dezena inteira, é de louvor. As que não são numeradas por dezenas inteiras são de milagre, com exceção de umas poucas, talvez cinco, que versam sobre as festas de Nossa Senhora.

Feitas essas considerações preliminares, vamos à leitura da Cantiga e, em seguida, à sua análise:

\section{Cantiga no 110}

ESTA É DE LOOR DE SANTA MARIA

Tant' é Santa Maria de ben mui comprida, que pera a loar tempo nos fal e vida.

E como pode per lingua seer loada a que fez porque Deus a ssa carne sagrada quis fillar e ser ome, per que foi mostrada sa deidad' en carne, vista e oyda?

Tant' é Santa Maria de ben mui comprida...

Ca tantos son os bẽens de Santa Maria, que lingua dizer todos nonos poderia, nen se fosse de ferro e noite e dia non calasse, que ante non fosse falida.

Tant' é Santa Maria de ben mui comprida... 
Se purgamẽo foss'o ceo estrelado e o mar todo tinta, que grand' é provado, e vivesse por sempr' un ome enssinado de scriver, ficar-ll-ia a mayor partida.

Tant' é Santa Maria de ben mui comprida...

O que chama a atenção, numa leitura atenta da Cantiga no 110 , é a forma como o poeta conduz o seu discurso, visando a deixar o leitor/ouvinte totalmente convicto das qualidades de Maria. Sem citar sequer uma dessas qualidades, o poeta atribui à Virgem um número infinito delas. E essa noção de infinito é dada pelas dimensões de tempo e espaço, dois conceitos que, por si só, já encerram essa idéia. Já no refrão o rei-poeta diz que o tempo de vida de um homem é insuficiente para que ele possa louvar Santa Maria à altura de seu merecimento: "pera a loar tempo nos fal e vida". Como no episódio bíblico de Jacó ${ }^{1}$ - o pastor que serviu a Labão para merecer o amor de sua filha Raquel -, em que faltaria tempo e vida para que ele pudesse provar o seu amor por ela, falta o mesmo, segundo o poeta, a quem se proponha a louvar Santa Maria. Camões, em seu conhecido soneto sobre a história de Jacó, conclui o último terceto dizendo que Jacó "mais servira, se não fora para tão longo amor tão curta a vida". Pode-se dizer que é a mesma idéia que está contida no refrão da Cantiga no 110 :

Tant'é Santa Maria de ben mui comprida, que pera a loar tempo nos fal e vida.

Neste caso, o contraste longo/curto do soneto camoniano longo amor/curta vida - se faz com a idéia de grande quantidade/ pouca durabilidade, isto é, a grande quantidade de virtudes de Maria é contrastante com a pouca durabilidade da vida de um homem, que, segundo o poeta, não pode louvá-la na medida do merecimento dela no espaço de tempo em que ele viver.

A tese anunciada no refrão é desenvolvida nas estrofes. Daí, a relação da Cantiga com as estratégias discursivas da Arte Retórica, de Aristóteles. O Livro 3, Capítulo XIII, da Arte Retórica reza que

${ }^{1}$ CAMÕES, 1981. 
O discurso comporta duas partes, pois necessariamente importa indicar o assunto de que se trata, e em seguida fazer a demonstração. Pelo que, uma vez indicado o assunto, é impossível não fazer a demonstração, como o é não fazer esta demonstração sem previamente ter anunciado o assunto; com efeito, quando se demonstra, demonstra-se alguma coisa e só se anuncia uma coisa a fim de a demonstrar. $^{2}$

O refrão da Cantiga outra função não cumpre senão a de indicar o tema, enquanto as estrofes fazem a demonstração daquilo que foi anunciado no refrão, correspondente, do ponto de vista da Retórica, à primeira parte do discurso. O desenvolvimento do assunto nas estrofes corresponde também ao desenvolvimento da hipérbole sobre a qual o refrão foi composto. Vejamos cada uma das estrofes como partes do desenvolvimento.

$\mathrm{Na}$ primeira delas, o poeta emprega um recurso bastante comum na oratória, que consiste em lançar uma pergunta, para a qual ele não admite uma resposta diversa da que ele espera ouvir. A condução para a resposta está na forma de elaborar a pergunta. É como se o ouvinte ficasse "sem saída", e não tivesse outro caminho senão concordar com o que a pergunta adianta em forma de resposta. Essa estratégia, no caso desta Cantiga, está em que, para mostrar a grandeza de Maria, o poeta chama à baila a autoridade máxima, que é Deus. Parafraseando de forma bem simplificada a primeira estrofe, poder-se-ia transformá-la na seguinte pergunta: "E como pode ser louvada por língua humana aquela que mereceu que o próprio Deus quisesse nascer dela?" Ora, haveria argumento mais forte do que esse para mostrar o quanto Maria é uma mulher especial e privilegiada por Deus, e portanto, digna de ser louvada?

E imediatamente depois dessa pergunta, o poeta passa a desenvolver, na segunda estrofe, um pensamento que se encadeia nessa pergunta não como resposta, mas como uma complementação de uma possível resposta, ou de uma resposta implícita na mente

${ }^{2}$ ARISTÓTELES, [s.d.]. 
do leitor. A estrofe se inicia com a palavra $c a$, que em português moderno significa 'porque, pois', e funciona como um marcador de continuação, ou seja, um elemento condutor do raciocínio para encaminhá-lo à conclusão pretendida pelo enunciador. E em seguida a esse ca, ou porque, que introduz nova ordem de argumentos, o poeta fala da impossibilidade de um homem, na sua condição de mortal, louvá-la. O poeta emprega a expressão língua de ferro para mostrar que ainda que a língua de um homem não fosse constituída da carne frágil de que o é, mas sim, de uma matéria muito mais resistente ao tempo, que é o ferro, esta língua não resistiria ao exaustivo trabalho de arrolar as qualidades de Santa Maria. A respeito do emprego da palavra lingua, quero observar que na primeira estrofe, a palavra parece ter sido empregada em sentido mais próximo de idioma. À leitura da primeira estrofe, portanto, pode parecer que a intenção do poeta fosse dizer que não há idioma suficientemente rico em adjetivos e expressões que desse conta de louvar Maria na proporção de suas qualidades. À leitura da segunda, com a palavra lingua empregada no sentido de 'órgão', introduz-se a ambigüidade do termo. Não há mais como determinar o sentido do emprego da palavra lingua na primeira estrofe, mesmo porque a escolha de um dos sentidos põe a perder a polissemia, que no texto literário tem um valor positivo. Ainda sobre o sentido de 'idioma' para a palavra lingua, vale lembrar novamente que o poeta, em toda a Cantiga, não cita explicitamente nenhuma qualidade de Maria. Sabe-se que a possibilidade de combinações para a formação de palavras de um dado idioma é infinita, mas a relação de adjetivos elogiativos, por mais extensa que seja, é limitada. Por isso, provavelmente, o poeta não se dá ao trabalho de citar uma qualidade que seja de Maria. Ao suprimir suas qualidades, e reforçar a idéia de que são tantas, o poeta implicitamente lhe atribui todas as qualidades que possam ser expressas por língua humana em uma dada língua ou idioma, e mais, aquelas que a pouca duração da vida de um homem não permite que sejam mencionadas.

Até aqui o poeta já encerrou duas verdades de sua tese: a de que não há língua que possa louvar Maria, por ter sido ela tão repleta 
de virtudes a ponto de ser escolhida por Deus para mãe do Salvador do mundo; e a de que a língua de quem se propuser a elogiá-la ainda que fosse de ferro, não poderia fazê-lo a contento sem que viesse a falhar.

Por fim, na terceira estrofe, a hipérbole que o poeta emprega passa também por uma comparação hipotética:

Se Céu = pergaminho

Se Mar $=$ tinta

e, na mesma esteira dessas hipóteses, sugere ao leitor que imagine um homem letrado, que fosse imortal, e dedicasse toda a sua vida ao trabalho de tecer os elogios que a Virgem merece.

Numa paráfrase dessa terceira e última estrofe, poderíamos mostrar como o poeta encerra seu louvor a Maria nesta cantiga, o que ele faz dizendo que "ainda que o céu estrelado fosse um pergaminho, e o mar imenso fosse tinta, e um homem letrado vivesse para sempre louvando a Virgem, ainda assim, a maior parte das virtudes dela ficaria por dizer".

Ora, o céu e o mar, por suas incontestáveis extensões, não raro servem à poesia ou à fala cotidiana para expressar aquilo que se quer apontar como grande ou excessivo. Esses elementos - céu e mar costumam vir à baila quando o que se pretende é dar a idéia de algo infinito.

E assim, o poeta reforça a idéia da hipérbole - que a comparação de qualquer coisa com esses elementos por si só já traz - ao afirmar que ainda assim, com este imenso pergaminho que poderia ser o céu, e com esta imensa quantidade de tinta que poderiam ser as águas do mar, a maior parte das qualidades da Virgem ficaria por dizer, à espera da criação de novas expressões e de mais extensão de pergaminho e maior quantidade de tinta.

Para concluir, quero considerar agora toda a Cantiga, a fim de chamar a atenção para o fato de que o poeta reúne as três estrofes na intenção de inculcar no seu ouvinte/leitor a certeza de que o valor de Maria é inquestionável e incomensurável, logo indizível. 


\section{Apêndice}

\section{Cantiga no 110}

ESTA É DE LOOR DE SANTA MARIA

Tant'é Santa Maria de ben mui comprida, que pera a loar tempo nos fal e vida.

E como pode per lingua seer loada a que fez porque Deus a ssa carne sagrada quis fillar e ser ome, per que foi mostrada sa deidad' en carne, vista e oyda?

Tant' é Santa Maria de ben mui comprida...

Ca tantos son os bẽens de Santa Maria, que lingua dizer todos nonos poderia, nen se fosse de ferro e noite e dia non calasse, que ante non fosse falida.

Tant' é Santa Maria de ben mui comprida...

Se purgamẽo foss' o ceo estrelado e o mar todo tinta, que grand' é provado, e vivesse por sempr' un ome enssinado de scriver, ficar-ll-ia a mayor partida.

Tant' é Santa Maria de ben mui comprida...

Transcrição da Cantiga no 110 para o português moderno

\section{Cantiga no 110}

ESTA É DE LOUVOR A SANTA MARIA

Tão plena de graças é Santa Maria

que, para louvá-la, nos falta tempo e vida.

E como pode por uma língua ser louvada aquela que mereceu que Deus quisesse por ela tomar sua carne sagrada e se tornar homem, graças ao que a sua divindade mostrada foi em carne, e vista e ouvida?

Tão plena de graças é Santa Maria... 
Pois tantas são as graças de Santa Maria, que uma língua não poderia dizê-las todas, - ainda que essa língua fosse de ferro, e noite e dia não se calasse -, sem que antes falhasse.

Tão repleta de qualidades é Santa Maria...

Se o céu estrelado fosse um pergaminho

e fosse tinta o mar, que como todos sabem é grande, e vivesse para sempre um homem letrado, ficar-lhe-ia por dizer a maior parte das graças que ela tem.

Tão repleta de qualidades é Santa Maria...

\section{Referências Bibliográficas}

ALFONSO X, el Sábio. Cantigas de Santa María. Edicion de Walter Mettmann. Madrid: Clásicos Castalia, 1988.

ARISTÓTELES. Arte Retórica e Arte Poética. Trad. Antônio P. de Carvalho. Rio de Janeiro: Ediouro, [s.d.].

CAMÕES, Luís de. Lírica. Edição preparada por Massaud Moisés. São Paulo: Cultrix, 1981.

\section{Resumo}

Neste artigo, é apresentada análise da Cantiga nํㅜ 110 das Cantigas de Santa Maria, de D. Afonso X, o Sábio. A análise incide na interpretação das expressões hiperbólicas com que o poeta louva Santa Maria.

\section{Resumé}

Dans ce texte, on présente une analyse de la chanson (cantiga) numéro 110, originaire de l'oeuvre Les Chansons de la Sainte Maire (Cantigas de Cantiga de Santa Maria) du roi D. Afonso X, le Savant. Cette analyse se dédie à l'interprétation des expressions hyperboliques par lesquelles le poète fait des éloges à la sainte Marie. 